\title{
Impacts of large-scale atmospheric circulation changes due to winter sea-ice retreat on Black Carbon transport and deposition to the Arctic
}

Luca Pozzoli $^{1}$, Srdan Dobricic ${ }^{1}$, Simone Russo $^{2}$, and Elisabetta Vignati ${ }^{1}$

5 'European Commission, Joint Research Centre (JRC), Directorate for Energy, Transport and Climate, Air and Climate Unit, Ispra (VA), 21027, Italy

${ }^{2}$ European Commission, Joint Research Centre (JRC), Directorate for Competences, Modelling, Indicators and Impact Evaluation Unit, Ispra (VA), 21027, Italy

Correspondence to: Luca Pozzoli (luca.pozzoli@jrc.ec.europa.eu)

a) BC Anthropogenic Emissions

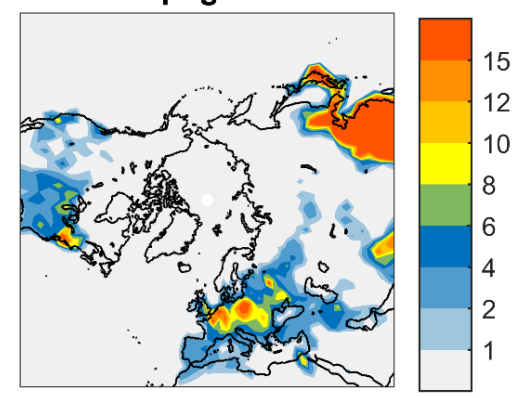

c) $\triangle \mathrm{BC}$ Emissions $2000-1980$

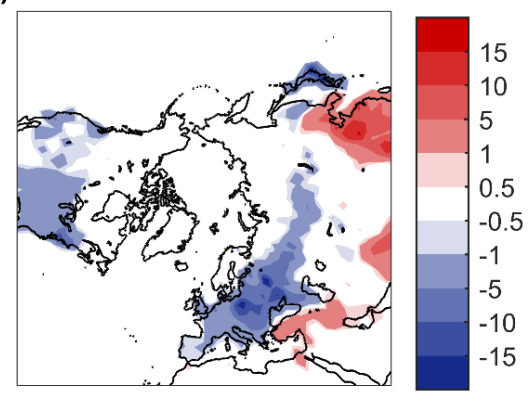

b) BC Wildfire Emissions

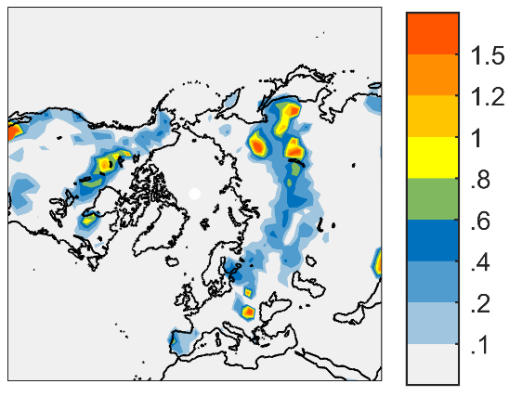

d) BC Emissions, 1980 - 2005

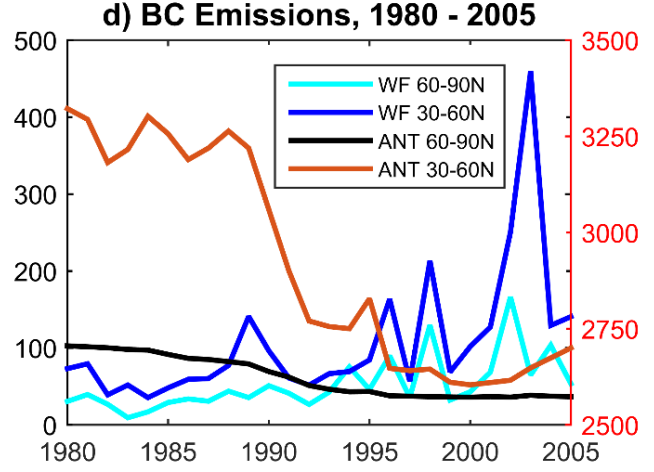

Figure S1 Overview of $\mathrm{BC}$ emissions above $30^{\circ} \mathrm{N}$ as used in the ECHAM5-HAMMOZ simulations: a) multi-annual mean (19802005) of total BC anthropogenic emissions $\left(\mathrm{Gg} \mathrm{year}^{-1}\right)$; b) multi-annual mean (1980-2005) of total BC wild fire emissions (Gg year 1); c) difference of $\mathrm{BC}$ total emissions $\left(\mathrm{Gg}_{\text {year }}{ }^{-1}\right)$ between years 2000 and 1980 ; d) annual variability of $\mathrm{BC}$ total anthropogenic

15 (ANT) and wild fire (WF) emissions $\left(\mathrm{Gg} \mathrm{year}^{-1}\right)$ at mid- $\left(30^{\circ} \mathrm{N}-60^{\circ} \mathrm{N}\right)$ and high-latitudes $\left(60^{\circ} \mathrm{N}-90^{\circ} \mathrm{N}\right)$ [ANT $30-60 \mathrm{~N}$ emissions are $^{-}$ displayed on the right y-axis]. 
a) Wet Dep. [kg/year] FIX1980
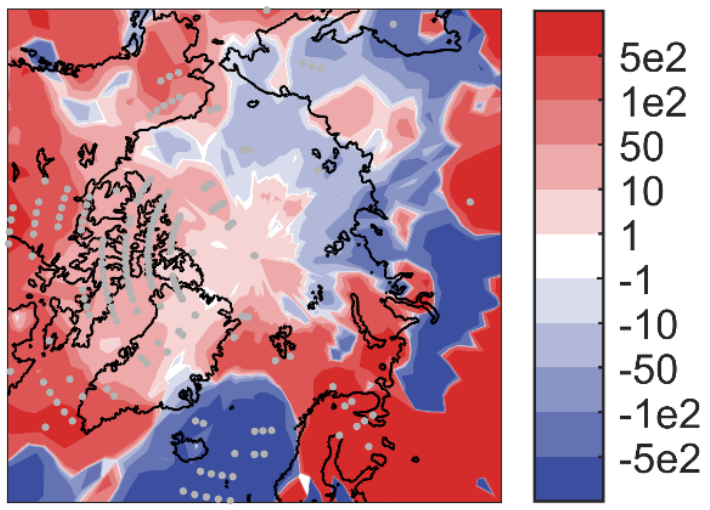

c) Srf.Conc. $\left[10^{-3} \mathrm{ng} / \mathrm{kg} / \mathrm{year}\right] \mathrm{FIX} 1980$
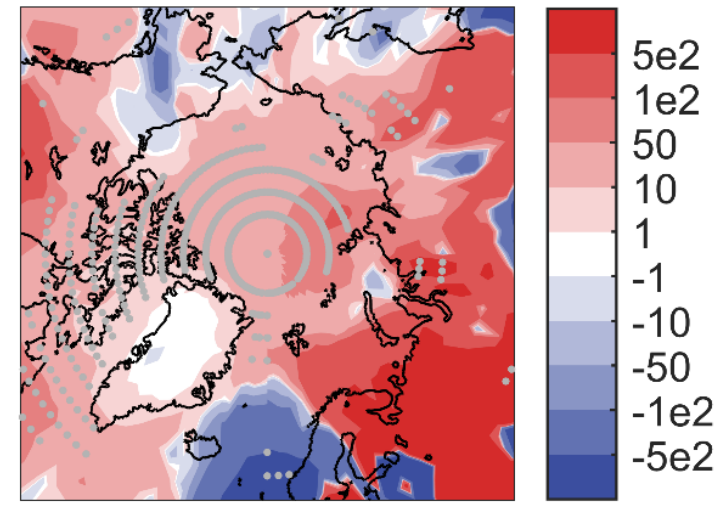

b) Dry Dep. $\left[10^{-3} \mathrm{~kg} / \mathrm{year}\right] \mathrm{FIX} 1980$

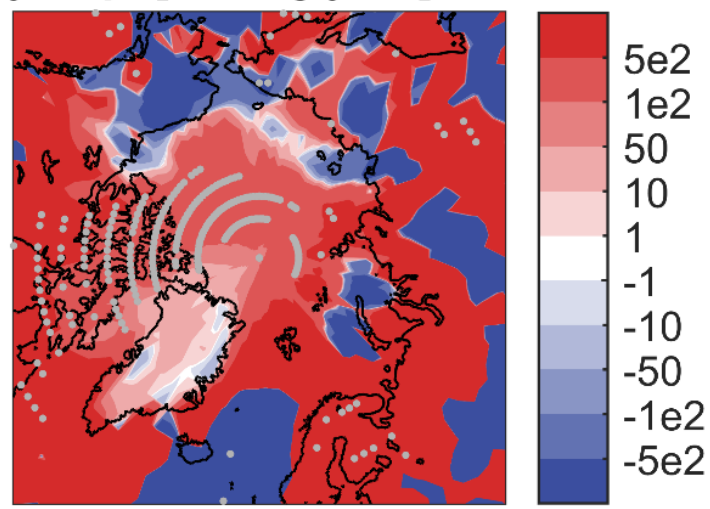

d) Load $\left[10^{-2} \mathrm{~kg} / \mathrm{year}\right] \mathrm{FIX} 1980$

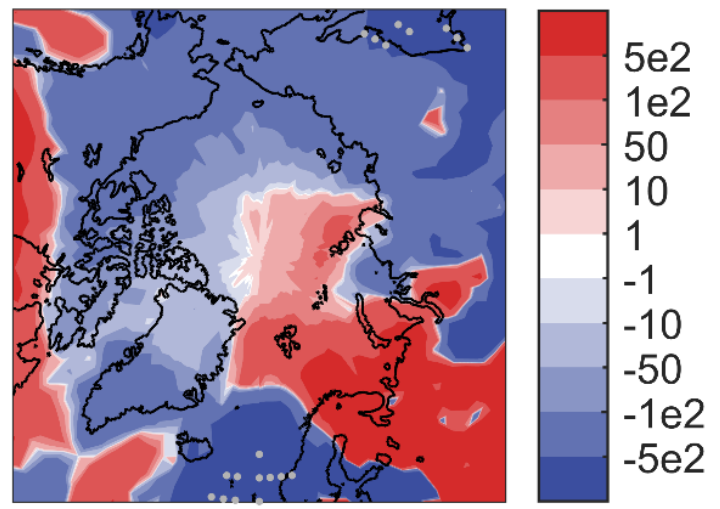

Figure S2 Winter (DJF) trends of BC wet deposition (a), dry deposition (b), surface concentration (d), and total load (d) for the

ECHAM5-HAMMOZ FIX1980 simulation. Grey dots represent the grid points with trend significant at $5 \%$ level. 


\section{BC Load $\left[10^{-2} \mathrm{~kg} / \mathrm{year}\right]$}

\section{FIX2000}

(1980-2005)

NCEP
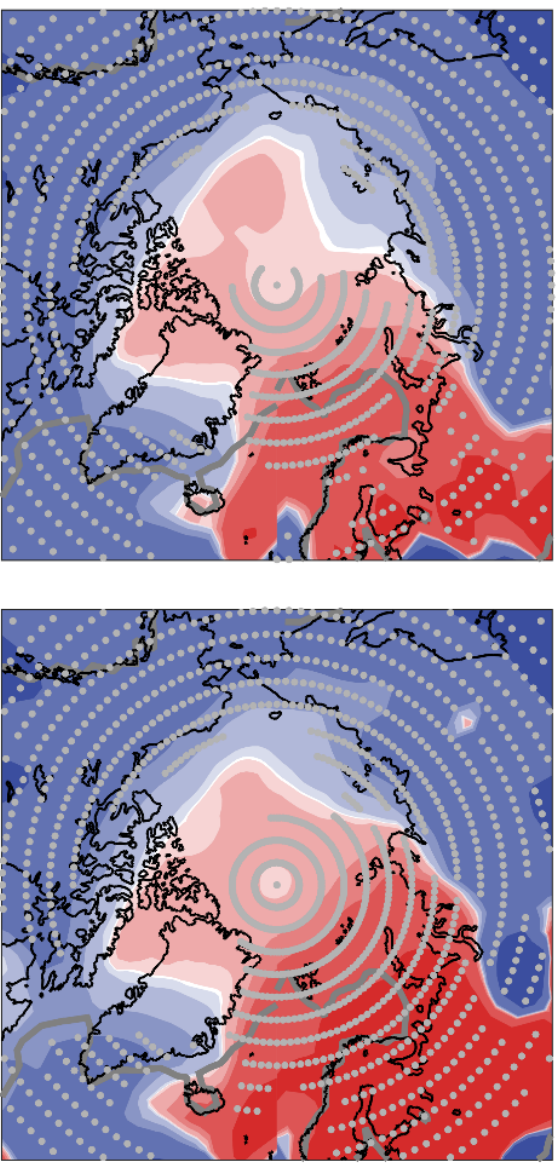

ERA
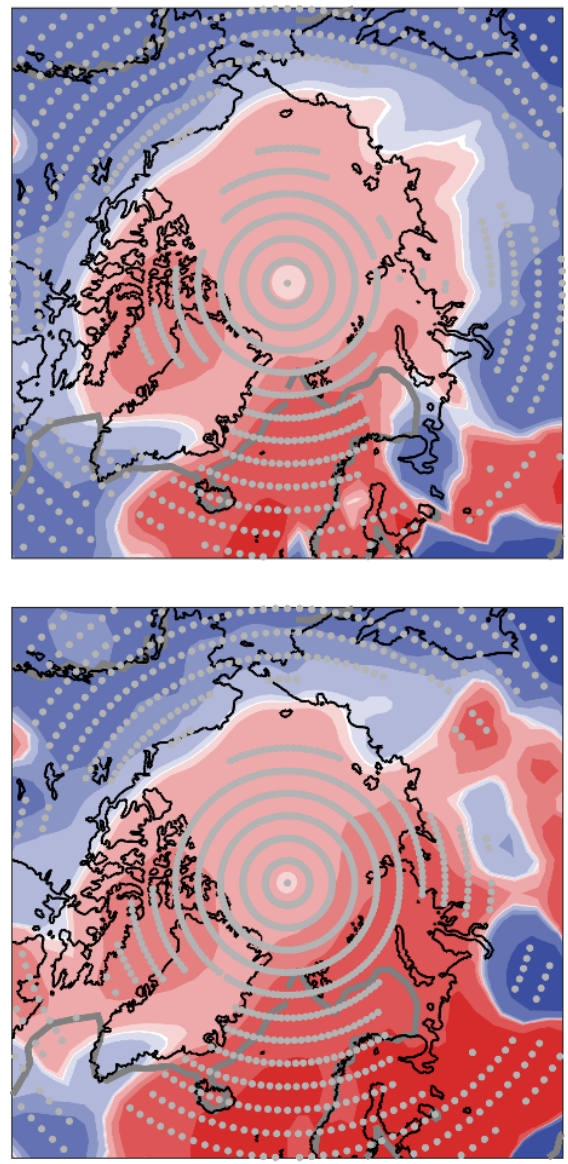

Figure S3 Four different estimates (see also Table 1) of total trends of maximum likelihood BC load associated to three atmospheric circulation patterns (Total=NAO+SB+ENSO). The grey line represents the mean winter sea ice and snow cover larger than $50 \%$ since 1980 to now. Grey dots represent the grid points with trend significant at $5 \%$ level. 


\section{BC Load [10 $0^{-2} \mathrm{~kg} /$ year]}

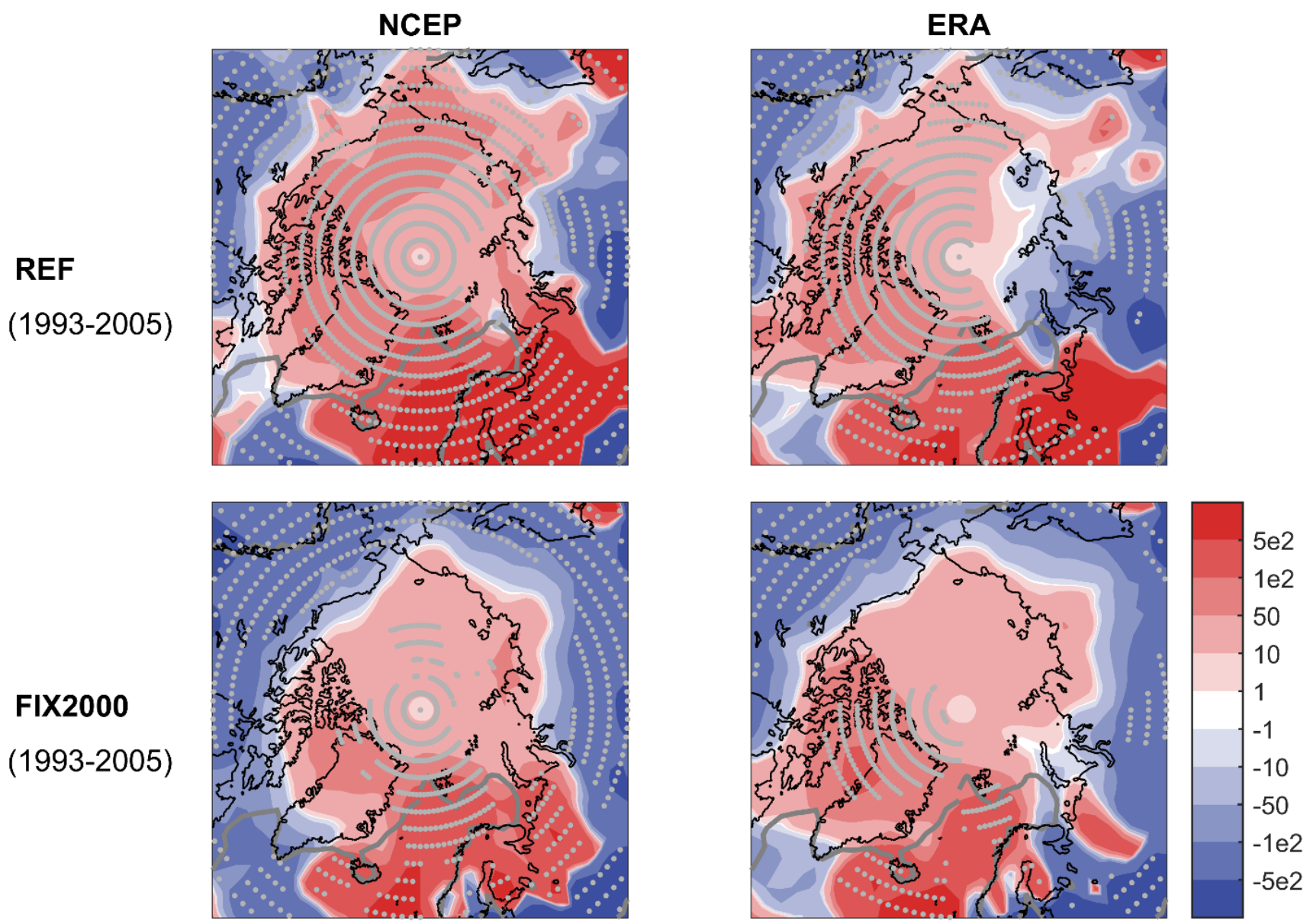

Figure S4 Four different estimates (see also Table 1) of total trends of maximum likelihood BC load associated to three atmospheric circulation patterns (Total=NAO+SB+ENSO). The grey line represents the mean winter sea ice and snow cover larger than $50 \%$ since 1980 to now. Grey dots represent the grid points with trend significant at $5 \%$ level. 

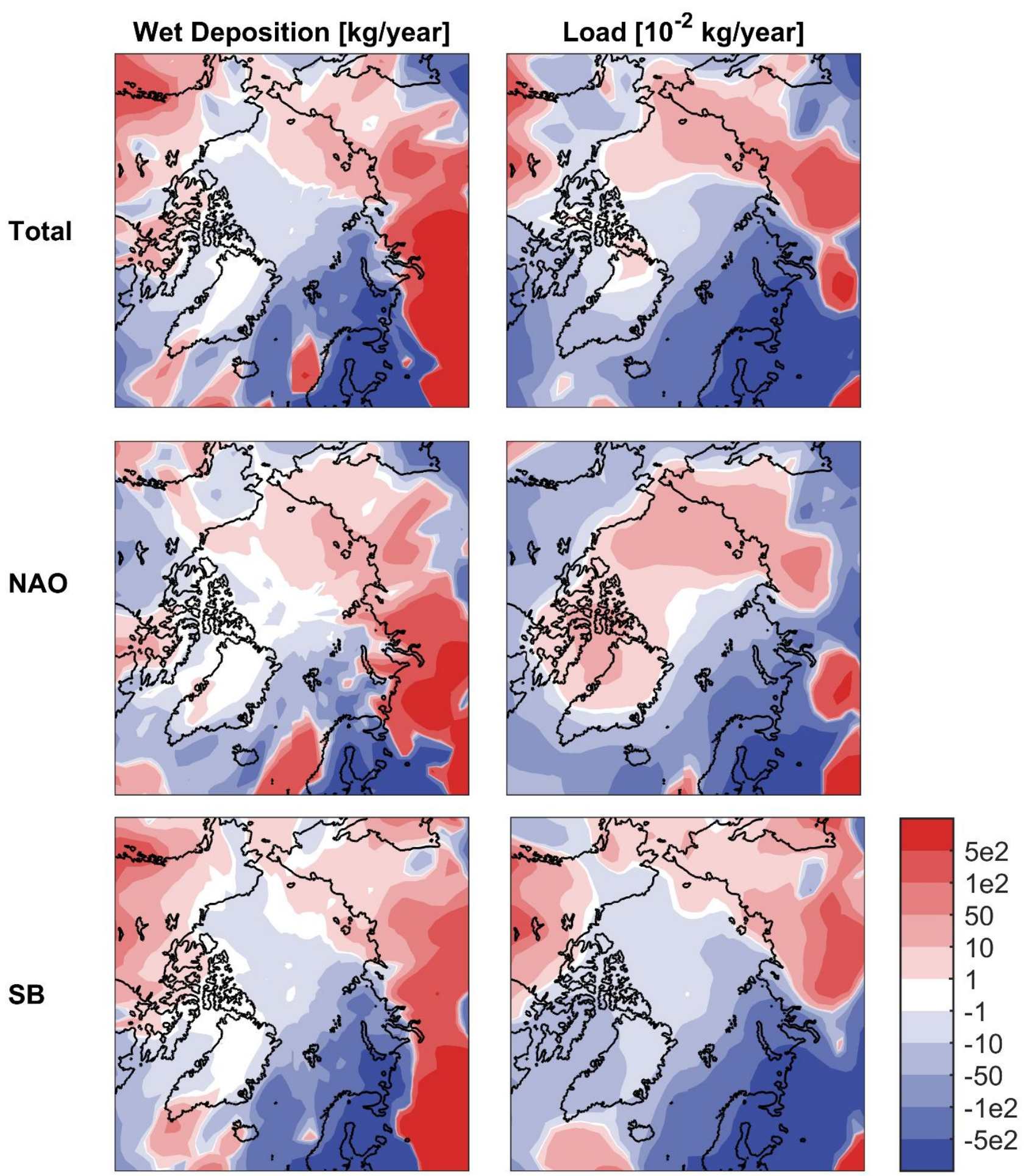

Figure S5 Differences between trend of MLE of BC wet deposition and load from the FIX2000 and FIX1980 chemistry-climate model simulations. 